\title{
EXTRAÇÃO DE FERRO DE ESMECTITA BRASILEIRA COM EMPREGO DO MÉTODO DITIONITO-CITRATO-BICARBONATO
}

Sidnei Quezada M. Leite ${ }^{\mathrm{a}}$, Carlos Henrique A. Colodete e Lídia Chaloub Dieguez

Núcleo de Catálise - Programa de Engenharia Química - COPPE/UFRJ

Rosane A. S. San Gil ${ }^{\text {b** }}$

Dep ${ }^{\text {to }}$ de Química Orgânica - Instituto de Química - UFRJ - 21949-900 - Rio de Janeiro - RJ

\begin{abstract}
IRON EXTRACTION FROM BRAZILIAN SMECTITE BY DITHIONITE-CITRATE-BICARBONATE METHOD. A natural clay from Campina Grande region (Paraíba, Brazil), with $8.57 \%$ of $\mathrm{Fe}_{2} \mathrm{O}_{3}$, was used to study the most appropriate condition to carry out the iron extraction, without altering the clay structure in a significant way. Samples were treated with the Dithionite-CitrateBicarbonate method (DCB) for 30 and 120 minutes $(\mathrm{pH}=9.1)$, and also with citric acid $(\mathrm{pH}=1.8$; time $=15 \mathrm{~min}$ ), at $75^{\circ} \mathrm{C}$. Conductivity measurements, X-ray fluorescence, $X$-ray diffraction, energydispersive spectrometry, electron-diffraction with transmission electron microscopy and textural evaluation by nitrogen adsorption were done. The treatment in a basic medium was more selective for iron removal than in acid condition. The time of 30 minutes, with $1.6 \mathrm{~g} \mathrm{Na} \mathrm{S}_{2} \mathrm{O}_{4} / 10 \mathrm{~g}$ clay, was the best condition for the iron extraction.
\end{abstract}

Keywords: brazilian clay; smectite; iron extraction.

\section{INTRODUÇÃO}

A busca de condições operacionais para extração de óxidos de ferro presentes em amostras de solo ou de argila natural, sem alterar de forma significativa a estrutura dos argilominerais, tem sido investigado por alguns pesquisadores ${ }^{1-7}$. Esse interesse é devido à necessidade de maior confiabilidade nas análises de $\operatorname{solos}^{1-4}$ e à necessidade de purificação de argila natural para fins catalíticos ${ }^{5-7}$.

Argilas naturais podem conter como impurezas diversos tipos de óxidos de ferro cristalinos ou amorfos, tais como: hematita $\left(\alpha-\mathrm{Fe}_{2} \mathrm{O}_{3}\right)$, goetita $(\alpha-\mathrm{FeOOH})$ e lepidocrocita $(\gamma$ $\mathrm{FeOOH}$ ), além de outras formas combinadas, como a magnetita $\left(\mathrm{FeO} . \mathrm{Fe}_{2} \mathrm{O}_{3}\right)$ e a ilmenita $\left(\mathrm{FeO} \cdot \mathrm{TiO}_{2}\right)^{1,7,8}$. No caso das esmectitas brasileiras, o ferro pode estar presente tanto sob a forma de óxidos isolados quanto na forma de substituições isomórficas na rede cristalina. Estas esmectitas têm sido empregadas na preparação de argilas pilarizadas, as quais são catalisadores para reações do tipo ácido-base. A presença de ferro na estrutura da argila leva à diminuição da estabilidade térmica, limitando o seu uso para fins catalíticos ${ }^{6,9}$.

$\mathrm{Na}$ literatura estão relatados alguns métodos para extração de óxidos e hidróxidos de ferro de argilas naturais e solos, destacando-se o método de Ditionito-Citrato-Bicarbonato (DCB, a sigla CBD é também utilizada) ${ }^{7,10}$. O método DCB utiliza ditionito de sódio na faixa de 0,50 a 1,0 grama para cada 10 gramas de argila, $40,0 \mathrm{~mL}$ de solução de citrato de sódio $0,30 \mathrm{~mol} / \mathrm{L}$ e $5,0 \mathrm{~mL}$ de solução de bicarbonato de sódio $1,0 \mathrm{~mol} / \mathrm{L}$. Este tratamento é realizado com controle de temperatura na faixa de 70 a $80^{\circ} \mathrm{C}$ por um período de 15 minutos ${ }^{7,10-12}$ e foi desenvolvido por Mehra \& Jackson ${ }^{11}$ para remover principalmente ferro sob a forma de óxido/hidróxido amorfo ou óxido cristalino, sem alterar a estrutura do material. No entanto, trabalhos posteriores têm sugerido que,

\footnotetext{
a Endereço permanente: Escola Técnica Federal de Química - Rio de Janeiro - RJ

b Dep ${ }^{\text {to }}$ Ciências Naturais - CCBS - UNIRIO - Rio de Janeiro - RJ e-mail: rsangil@iq.ufrj.br
}

dependendo das condições de tratamento e do tipo da argila, é possível que a estrutura seja afetada $a^{7,13-15}$

No presente trabalho, avaliou-se a influência do tempo e do $\mathrm{pH}$ no processo de extração de ferro de uma amostra natural de esmectita brasileira, proveniente da região de Campina Grande (Paraíba, Brasil), empregando-se os métodos DCB e o ácido cítrico. Foram feitas medidas de condutividade e absorção atômica das águas de lavagem; as amostras sólidas foram caracterizadas por fluorescência de raios-X (FRX), difração de raios-X (DRX), análise química de micro-regiões por espectrometria de energia dispersiva acoplado à microscopia eletrônica de transmissão (EDS/ MET) e avaliação textural por adsorção de nitrogênio.

\section{PARTE EXPERIMENTAL}

\section{Argila Natural}

Uma amostra de argila natural (ARG-Natural), proveniente da região de Campina Grande (Paraíba, Brasil), com granulometria de 200 mesh e capacidade de troca catiônica de 1,0 meq/g, foi purificada com o objetivo de minimizar as impurezas normalmente presentes, tais como quartzo e feldspato.

\section{Purificação da Argila Natural}

Durante 15 dias, 100 gramas de argila natural foram mantidas em 1,0 litro de solução de $\mathrm{NaCl} 2,0 \%(\mathrm{~m} / \mathrm{v})$, realizando trocas diárias desta solução para propiciar a troca dos íons interlamelares por íons sódio. Após esta etapa, a suspensão foi peneirada (peneira de 270 mesh) para remoção da fração areia, formada por partículas com diâmetro superior a 74 Mm (diâmetro da malha). Em seguida, a fração não retida na peneira foi transferida para uma proveta de 1,0 litro para efetuar a separação das frações argila e silte por sedimentação. A suspensão foi mantida em repouso por $24 \mathrm{~h}$, para que as partículas com diâmetro superior a $2 \mu \mathrm{m}$ fossem sedimentadas, seguida de sucção dos $20 \mathrm{~cm}$ superiores da suspensão rica em argila. Esta fração foi centrifugada e lavada até uma condutividade inferior a $30 \mu \mathrm{S}$, utilizando-se água destilada e deionizada com condutividade igual a $5 \mu \mathrm{S}$, o que resultou na amostra de argila purificada denominada ARG-01. 


\section{Extração de Ferro}

Tanto no método de Ditionito-Citrato-Bicarbonato clássico quanto no modificado, foram utilizados $40,0 \mathrm{~mL}$ de solução de citrato de sódio $0,30 \mathrm{~mol} / \mathrm{L}, 5,0 \mathrm{~mL}$ de solução de bicarbonato de sódio $1,0 \mathrm{~mol} / \mathrm{L}$ e $0,80 \mathrm{~g}$ de ditionito de sódio por ciclo de tratamento para cada $10 \mathrm{~g}$ argila $(\mathrm{pH}$ inicial $=9,1)$; o método de Ácido Cítrico utilizou $40,0 \mathrm{~mL}$ de ácido cítrico $0,30 \mathrm{~mol} / \mathrm{L}$ para cada $10 \mathrm{~g}$ de argila $(\mathrm{pH}$ inicial $=1,8) . \mathrm{Na}$ Figura 1 está apresentado o fluxograma do estudo realizado com as respectivas condições de tratamento empregadas para extração de ferro. $O$ ciclo de tratamento citado na Figura 1 para os métodos de DCB refere-se a quantidade de ditionito de sódio adicionada. A amostra ARG-02, tratada com o método DCB clássico, foi obtida a partir da amostra ARG-01. Estudou-se a influência do aumento do tempo de tratamento (ARG-03) e da mudança do pH do meio (ARG-04). As amostras ARG-03 e ARG-04 foram obtidas a partir da amostra ARG-02. A primeira etapa do tratamento teve como objetivo a retirada de ferro não estruturaèŸ dando origem a amostra ARG-02 que foi o material de partida para o estudo da retirada de ferro estrutural. O objetivo foi buscar condições de máxima remoção de ferro, visando uma argila purificada com modificações estruturais minimizadas.

Ao final de cada tratamento, as amostras foram lavadas, controlando-se a condutividade da água de lavagem até um valor de $30 \mu \mathrm{S}$. Em seguida, as amostras foram centrifugadas e secas à temperatura de $60^{\circ} \mathrm{C}$.

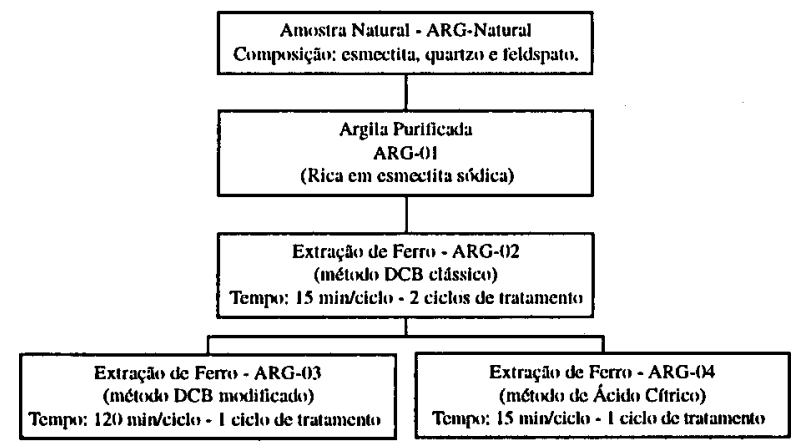

Figura 1. Fluxograma do estudo de extração de ferro, com as respectivas condições de tratamento e códigos das amostras.

\section{Caracterização das Amostras}

Foi feito o acompanhamento da condutividade das soluções resultantes das lavagens das amostras até alcançar o valor de $30 \mu \mathrm{S}$, utilizando condutivímetro Orion modelo 115. A fim de controlar a extração de alumínio e de ferro, foram feitas análises químicas por absorção atômica da primeira água de lavagem, utilizando equipamento Perkin Elmer modelo 1100B. A água empregada nos ensaios foi destilada e deionizada apresentando condutividade na faixa de $5 \mu \mathrm{S}$ e $\mathrm{pH} \cong 6,5$.

A composição química das amostras sólidas foi obtida por fluorescência de raios X (FRX), utilizando-se um instrumento Philips 1480, equipado com tubo de $\mathrm{Cu}$.

As micrografias foram obtidas por microscopia eletrônica de transmissão (MET) empregando um instrumento JEOL JEM 2000 FX, equipado com difração de elétrons (DE) e análise química de micro-regiões por espectrometria de energia dispersiva (EDS). O material foi depositado sobre grades de cobre, de 200 mesh recobertas com Formvar, por gotejamento da suspensão contendo $1,0 \%(\mathrm{~m} / \mathrm{v})$ de argila em álcool etílico, previamente mantida em ultra-som por 10 minutos.

Os difratogramas de raios $\mathrm{X}$ foram obtidos pelo método do pó, utilizando-se um instrumento Philips 1710, equipado com tubo de $\mathrm{Cu}$ e monocromador de grafite, operando com potência de $40 \mathrm{KV}-35 \mathrm{~mA}$.

As isotermas de adsorção-dessorção de $\mathrm{N}_{2}$ foram obtidas à temperatura de $77 \mathrm{~K}$ (banho de nitrogênio líquido), após pré-tratamento a vácuo à temperatura de $60^{\circ} \mathrm{C}$ por 5 horas para remover umidade e gases adsorvidos fisicamente. Empregou-se o equipamento Micromeritics A.S.A.P. 2000. Determinou-se o volume total de poros $\left(\mathrm{V}_{\mathrm{p}}\right)$ a $\mathrm{P} / \mathrm{P}_{\mathrm{o}}=0,98$, a área específica $\left(\mathrm{S}_{\mathrm{BET}}\right)$ pelo método de BET e o diâmetro de poro $\left(\mathrm{D}_{\mathrm{p}}\right)$ através da relação entre o volume de poros e a área específica: $\mathrm{D}_{\mathrm{P}}=\mathrm{V}_{\mathrm{p}} / 4 \mathrm{~S}_{\mathrm{BET}}$. $\mathrm{O}$ volume de microporos e a área externa $\left(\mathrm{S}_{\mathrm{EXT}}\right)$ foram estimados a partir da isoterma de adsorção de nitrogênio, utilizando-se como forma de tratamento dos dados o método t, conhecido como "t-Plot". O valor de $t$, espessura estatística da camada adsorvida, foi calculado utilizando a expressão de Harkins \& Jura ${ }^{16}$ :

$t=\left[\frac{13,99}{0,034-\log \left(P / P_{\mathrm{w}}\right)}\right]^{0,5}$

onde $\mathrm{P} / \mathrm{P}_{\mathrm{o}}$ é a relação entre a pressão do meio $(\mathrm{P})$ e a pressão de saturação de nitrogênio $\left(\mathrm{P}_{\mathrm{o}}\right)$ à temperatura de análise $(\mathrm{T}=77 \mathrm{~K})$.

\section{RESULTADOS E DISCUSSÃO}

\section{Caracterização da Argila Natural}

Na Figura 2 está apresentado o difratograma de raios $X$ da argila natural (ARG-Natural), que apresentou padrões de argila esmectítica $(\mathrm{d}=15,43 \AA$ e $\mathrm{d}=4,49 \AA)$, quartzo-alfa $(\mathrm{d}=3,34$ $\AA$ e $\mathrm{d}=4,27 \AA$ ) e feldspatos cálcico e potássico ( $\mathrm{d}=3,19 \AA$ e $\mathrm{d}=3,23 \AA)^{7}$. O pico de difração situado na faixa de $2 \Theta$ igual a $60^{\circ}$, correspondente ao plano de difração (060), apresenta uma distância igual a 1,49 ̊̊, que é característico de esmectita dioctaédrica ${ }^{7,10}$. Portanto, a camada octaédrica deve ser constituída, principalmente, por metais com carga $3+$, tais como alumínio e ferro.

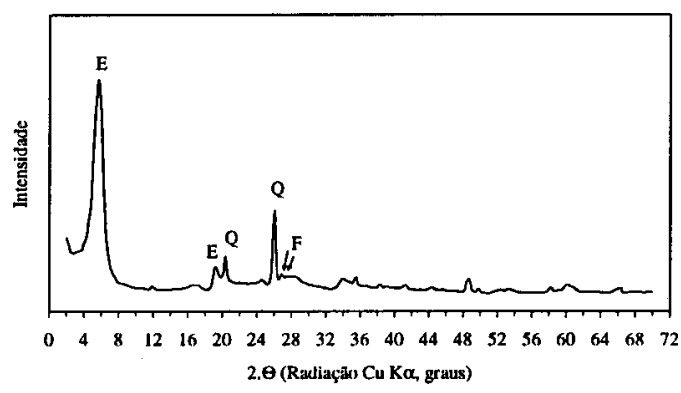

Figura 2. Difratograma de raios $X$ da amostra natural (ARG-Natural). Na Figura estão assinalados os picos de difração referentes aos padrões de argila esmectita $(E)$, quartzo-alfa $(Q)$ e feldspatos cálcico e potássico $(F)$.

$\mathrm{Na}$ Tabela 1 está apresentado o resultado de análise química da argila natural obtido por FRX. Além dos teores de $\mathrm{SiO}_{2}$ e $\mathrm{Al}_{2} \mathrm{O}_{3}$ normalmente encontrados nos argilominerais esmectíticos, estão presentes $8,57 \%$ de $\mathrm{Fe}_{2} \mathrm{O}_{3}$. Este teor alto de ferro é característico das argilas esmectíticas do Brasil ${ }^{8}$, e contribui para o abaixamento da temperatura de desidroxilação, o que diminui a estabilidade térmica do material.

Na Figura 3 está apresentada a micrografia da argila natural (ARG-Natural) obtida por MET. Na micrografia, obtida por dupla exposição, está assinalada a partícula "P" e a respectiva figura de micro-difração de elétrons (DE). São observadas três fases, que se mostram como aglomerados folheados e pequenos cristais escuros (partícula "P") e claros de formato regular. A micro-difração de elétrons da partícula "P" ressalta a cristalinidade desta partícula. 
Tabela 1. Análise química obtida por FRX da argila natural (ARG-Natural).

\begin{tabular}{cc}
\hline Componentes & Teor $(\%)$ \\
\hline $\mathrm{SiO}_{2}$ & 63,70 \\
$\mathrm{Al}_{2} \mathrm{O}_{3}$ & 20,18 \\
$\mathrm{Fe}_{2} \mathrm{O}_{3}$ & 8,57 \\
$\mathrm{Na}_{2} \mathrm{O}$ & 0,53 \\
$\mathrm{~K}_{2} \mathrm{O}$ & 0,54 \\
$\mathrm{CaO}$ & 0,98 \\
$\mathrm{MgO}$ & 4,22 \\
$\mathrm{TiO}_{2}$ & 1,10 \\
$\mathrm{P}_{2} \mathrm{O}_{5}$ & 0,05 \\
\hline
\end{tabular}

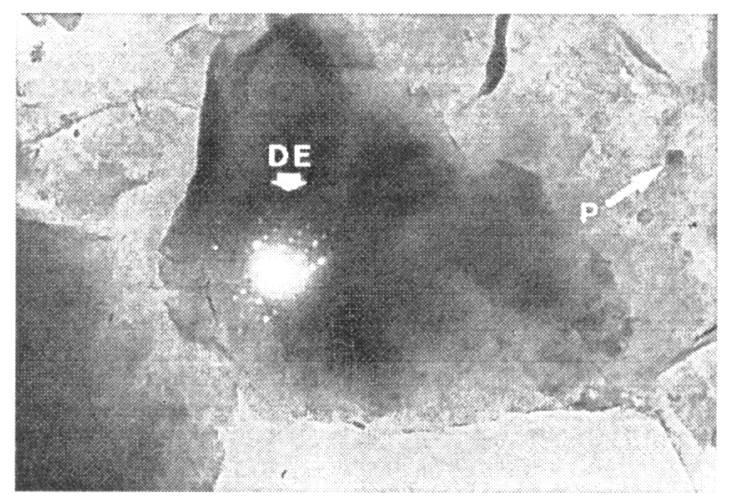

Figura 3. Micrografia da amostra ARG-Natural obtida por MET. Na Figura está assinalada a partícula $P$ e a respectiva Figura de microdifração de elétrons (DE) obtida por dupla exposição

Na Figura 4 está apresentada a análise química da partícula "P", assinalada na Figura 3, obtida por EDS/MET. A análise mostra que a partícula "P" é constituída principalmente por titânio. A presença de titânio já havia sido detectada pela análise química por FRX (Tabela 1). O titânio pode estar presente tanto na forma de óxidos isolados (e.g. $\mathrm{TiO}_{2}$ ), quanto na forma de óxidos mistos (e.g. $\mathrm{FeO} . \mathrm{TiO}_{2}$ ), ou ainda inserido na estrutura da argila como substituição isomórfica ${ }^{7,8}$. A detecção dos elementos $\mathrm{Si}, \mathrm{Al}, \mathrm{V}$ e $\mathrm{Fe}$, com baixa intensidade, deve ser devido à presença de partículas de argila agregadas à partícula "P".

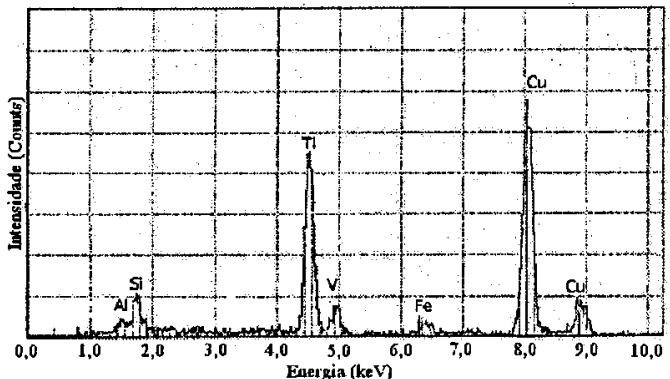

Figura 4. Análise química de micro-regiões obtida por EDS/MET da partícula $P$ observada na micrografia da Figura 3. O elemento $\mathrm{Cu}$ refere-se ao material da grade de suporte da amostra.

Com o objetivo de identificar o composto contendo titânio presente na amostra, foram obtidas figuras de difração de elétrons (DE), conforme está mostrado na Figura 3. A partir da comparação dos planos de difração, obtidos com o tratamento de dados das figuras de DE, com os padrões de difração publicados na literatura ${ }^{17}$, pode-se sugerir que o composto presente é o mineral rutilo $\left(\mathrm{TiO}_{2}\right)$.
Na Figura 5 está apresentada a análise química dos aglomerados de argila, obtida por EDS/MET. É importante citar que não foi possível obter figura de difração de elétrons da fase argila, já que se trata de uma estrutura de baixa cristalinidade. A análise mostra a presença de ferro, silício e alumínio, além de cátions interlamelares, não sendo observada a presença de titânio. Este resultado sugere a presença de ferro na estrutura da argila em substituições isomórficas. Entretanto, é também possível que esteja sendo detectado ferro fora da estrutura sob a forma de óxido ou hidróxido nos agregados de argila.

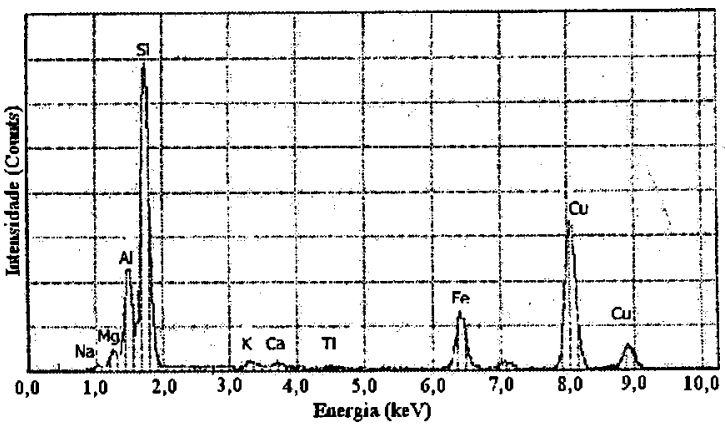

Figura 5. Análise química de micro-regiões obtida por EDS/MET da fase argila (aglomerados) observada na micrografia (Figura 3). O elemento $\mathrm{Cu}$ refer-se ao material da grade de suporte da amostra.

\section{Caracterização das Águas de Lavagem}

Normalmente, o acompanhamento da lavagem para a retirada de íons cloreto na etapa de purificação da argila natural é feito por teste de precipitação de $\mathrm{AgCl}$, pela adição de gotas de solução de $\mathrm{AgNO}_{3}$ (solubilidade do $\mathrm{AgCl}=1,04 \times 10^{-5} \mathrm{~mol} / \mathrm{L}$ ). Por este método, não foi observada precipitação de $\mathrm{AgCl}$ a partir da quarta lavagem. Na Figura 6 está apresentada a variação da condutividade da água em função do número de lavagens necessário para atingir a condutividade de $30 \mu \mathrm{S}$. Pode-se observar que a condutividade ainda é elevada após a quarta lavagem. Desta forma, os resultados mostram que o método de acompanhamento através das medidas de condutividade apresenta maior sensibilidade em comparação com os testes de precipitação com $\mathrm{AgCl}$. De um modo geral, com nove lavagens a condutividade atinge um valor médio de $30 \mu \mathrm{S}$, não sendo necessário um número maior de lavagens.

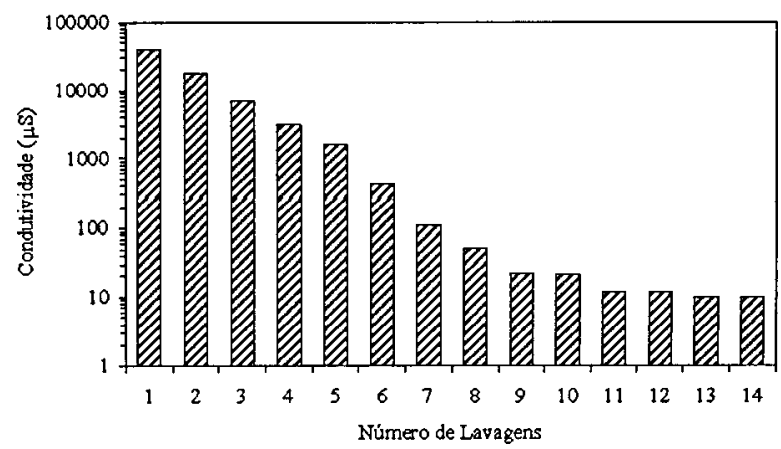

Figura 6. Influência do número de lavagens nas medidas de condutividade das águas de lavagem.

Na Tabela 2 estão apresentados os resultados de análise química das soluções resultantes da primeira lavagem dos sólidos após os tratamentos para remoção de ferro. Os resultados indicam que há remoção de ferro com o tratamento de DCB clássico (ARG-02) de forma acentuada em comparação com o alumínio, sugerindo maior seletividade para remoção de ferro, 
o que está em concordância com a literatura ${ }^{10,12}$. Por outro lado, também é observada a remoção de cálcio e magnésio na condição de DCB clássico.

Tabela 2. Percentuais de alumínio, ferro, cálcio e magnésio presentes nas águas de lavagens, extraídos após cada etapa de tratamento.

\begin{tabular}{llllc}
\hline Etapa de Tratamento & \multicolumn{4}{c}{ Percentual de metal removido ${ }^{\mathbf{a}}(\%)$} \\
& $\mathrm{Al}$ & $\mathrm{Fe}$ & $\mathrm{Ca}$ & $\mathrm{Mg}$ \\
\hline ARG-01ØARG-02 & 0,1 & 1,6 & 0,4 & 0,3 \\
ARG-02ØARG-03 & 0,1 & 0,2 & - & - \\
ARG-02ØARG-04 & 0,8 & 0,7 & - & - \\
\hline
\end{tabular}

a Valores obtidos por absorção atômica da primeira água de lavagem.

A presença de magnésio nas águas de lavagem sugere que parte deste elemento possa estar situado no espaço interlamelar como cátion trocável, embora tenha havido uma etapa anterior de troca iônica com sódio (ARG-01). É importante citar que o magnésio deve estar situado preferencialmente na rede cristalina da argila, na camada octaédrica, em baixa concentração, já que a análise de DRX do material natural indica que se trata de uma esmectita dioctaédrica.

No caso do tratamento em meio ácido (ARG-04), é verificada uma maior retirada de ferro e de alumínio em relação ao tratamento em meio básico com maior tempo (120 min, ARG-03). É importante ressaltar que o tratamento em meio ácido não contém agente redutor na mistura reacional, enquanto o tratamento em meio básico utiliza ditionito de sódio. Alguns autores relatam a importância da presença de um agente redutor juntamente com um complexante no processo de remoção de ferro, para tornar o meio reacional mais seletivo ${ }^{13-15}$.

\section{Avaliação das Argilas Tratadas}

$\mathrm{Na}$ Tabela 3 estão apresentados os resultados de razão mássica $\mathrm{SiO}_{2} / \mathrm{Al}_{2} \mathrm{O}_{3}$ e $\mathrm{SiO}_{2} / \mathrm{Fe}_{2} \mathrm{O}_{3}$ obtidos a partir das análises químicas feitas por FRX das amostras sólidas. É verificada uma variação da razão mássica $\mathrm{SiO}_{2} / \mathrm{Fe}_{2} \mathrm{O}_{3}$ na etapa de purificação da argila (ARG-Natural $\varnothing$ ARG-01), que pode estar associada à retirada da fração areia (quartzo) e da fração silte (feldspato) da amostra natural. Por outro lado, a razão mássica $\mathrm{SiO}_{2} / \mathrm{Al}_{2} \mathrm{O}_{3}$ não foi afetada, o que sugere remoção de alumínio e de silício na mesma proporção.

Tabela 3. Razões mássicas de $\mathrm{SiO}_{2} / \mathrm{Al}_{2} \mathrm{O}_{3}$ e $\mathrm{SiO}_{2} / \mathrm{Fe}_{2} \mathrm{O}_{3}$ obtidas a partir das análises químicas feitas por FRX das amostras sólidas natural, purificada e após tratamentos para remoção de ferro.

\begin{tabular}{lcc}
\hline Amostra & $\begin{array}{c}\mathrm{SiO}_{2} / \mathrm{Al}_{2} \mathrm{O}_{3} \\
\text { (massa/massa) }\end{array}$ & $\begin{array}{c}\mathrm{SiO}_{2} / \mathrm{Fe}_{2} \mathrm{O}_{3} \\
(\mathrm{massa} / \mathrm{mass})\end{array}$ \\
\hline ARG-Natural & 3,2 & 7,4 \\
ARG-01 & 3,2 & 6,7 \\
ARG-02 & 3,2 & 7,6 \\
ARG-03 & 3,3 & 8,0 \\
ARG-04 & 3,5 & 8,2 \\
\hline
\end{tabular}

O tratamento da argila ARG-01 pelo método DCB clássico (ARG-02) é, a princípio, adequado, já que há um aumento da razão mássica $\mathrm{SiO}_{2} / \mathrm{Fe}_{2} \mathrm{O}_{3}$ sem alteração da razão mássica $\mathrm{SiO}_{2} /$ $\mathrm{Al}_{2} \mathrm{O}_{3}$. É importante citar que este tratamento deveria promover somente remoção de ferro não-estrutural, sem retirar o ferro da estrutura da argila, embora modifique seu número de oxidação ${ }^{15}$, de $\mathrm{Fe}^{3+}$ para $\mathrm{Fe}^{2+}$.
Os resultados da razão mássica $\mathrm{SiO}_{2} / \mathrm{Fe}_{2} \mathrm{O}_{3}$ para os tratamentos em meio básico em 120 minutos (ARG-03) e em meio ácido (ARG-04) indicam aumento da remoção de ferro para ambos os tratamentos. De acordo com a análise das águas de lavagem (Tabela 2), o tratamento em meio básico apresenta maior seletividade para remoção de ferro, sem remover alumínio de forma significativa. Isto indica que não há ataque expressivo à estrutura da argila no tratamento feito em meio básico. No entanto, no tratamento realizado em meio ácido, tanto a análise da água de lavagem, quanto a razão mássica $\mathrm{SiO}_{2} /$ $\mathrm{Al}_{2} \mathrm{O}_{3}$ indicam uma perda de alumínio estrutural.

Na Figura 7 estão apresentados os difratogramas de raios $\mathrm{X}$ obtidos para as amostras purificada (ARG-01) e tratadas (ARG02, ARG-03 e ARG-04). Os difratogramas indicam a presença de esmectita, quartzo e feldspato, mesmo após a etapa de fracionamento para a purificação da fração esmectita. Isto pode ser explicado pela condição em que se encontrava a amostra de argila natural, moída com granulometria de 270 mesh. Na Tabela 4 estão apresentados os valores de espaçamento basal $\mathrm{d}(001)$ e cristalinidade, estimados a partir dos difratogramas das amostras natural (Figura 2), purificada e tratadas para remoção de ferro (Figura 7).

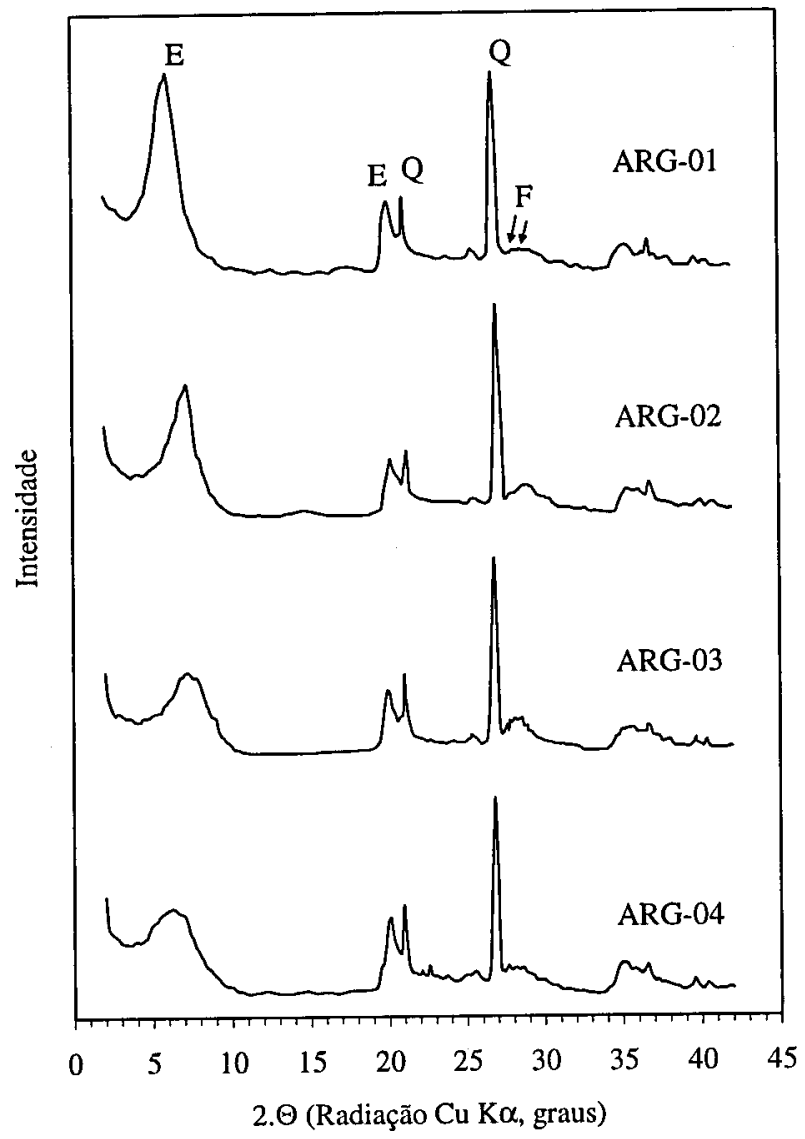

Figura 7. Difratogramas de raios $X$ das amostras, secas à temperatura de $60^{\circ} \mathrm{C}$, purificada (ARG-01), tratada com DCB clássico (ARG02), tratada com DCB modificado (ARG-03) e tratada com ácido cítrico (ARG-04). Na figura estão assinalados os picos de difração referentes à esmectita $(E)$, quartzo-alfa $(Q)$ e feldspatos $(F)$.

Após a purificação da argila natural, verifica-se uma pequena diminuição do espaçamento basal, de 15,2 para 14,5 $\AA$. Este resultado pode ser atribuído ao enriquecimento da intercamada com íons sódio, após a etapa de troca com $\mathrm{NaCl}$. A pequena queda de cristalinidade pode ser devida à possível heterogeneidade entre as camadas durante a etapa de secagem do material. 
Tabela 4. Espaçamento basal d(001) e cristalinidade obtidos a partir dos difratogramas das amostras natural, purificada e tratadas para retirada de ferro.

\begin{tabular}{lcc}
\hline Amostra & $\begin{array}{c}\text { Espaçamento basal d(001) } \\
(\AA)\end{array}$ & Cristalinidade $^{\mathbf{a}}$ \\
\hline ARG-Natural & 15,2 & 0,90 \\
ARG-01 & 14,5 & 0,79 \\
ARG-02 & 12,3 & 0,78 \\
ARG-03 & 11,8 & 0,72 \\
ARG-04 & 13,8 & 0,56 \\
\hline
\end{tabular}

a Determinada pela fórmula de Biscaye $^{7}$, que é a relação entre a distância do vale ao topo do pico (vale) e a altura do pico à projeção do vale (pico): Cristalinidade $=\langle$ vale $\rangle \mid\langle$ pico $\rangle$.

No caso do tratamento clássico para remoção de ferro não estrutural, a amostra ARG-02 praticamente não apresenta mudança da cristalinidade em comparação com a amostra purificada (ARG-01). Já os tratamentos com DCB modificado (ARG-03) e com ácido cítrico (ARG-04) fornecem amostras com maiores perdas de cristalinidade em relação à amostra ARG-02. O difratograma de raios $X$ da amostra ARG-04 indica que esta é a amostra com menor cristalinidade, o que sugere que o tratamento feito em meio ácido é mais agressivo à estrutura da argila em relação aos tratamentos em meio básico. Este resultado está coerente com o obtido anteriormente por análise química, que mostra retirada de alumínio.

Os tratamentos com DCB clássico (ARG-02) e modificado (ARG-03) promovem uma diminuição do espaçamento basal d(001) em comparação com a amostra purificada (ARG-01), apresentando valores na faixa de $12 \AA$. Este fato é menos expressivo no caso do tratamento em meio ácido (ARG-04). Este resultado pode ser explicado considerando-se que em meio ácido não há agente redutor, portanto a distribuição original de $\mathrm{Fe}^{3+} / \mathrm{Fe}^{2+}$ não deve ser alterada. Por outro lado, nos tratamentos com DCB a redução $\mathrm{Fe}^{3+}$ a $\mathrm{Fe}^{2+}$ pode acarretar na aproximação das lamelas, devido à maior atração com os cátions da intercamada, o que causaria diminuição no espaçamento basal.

$\mathrm{Na}$ Figura 8 estão apresentadas as isotermas de adsorçãodessorção obtidas para as amostras natural (ARG-Natural), tratadas com DCB clássico (ARG-02), com DCB modificado (ARG-03) e com ácido cítrico (ARG-04). Na Figura 9 estão apresentadas as curvas de "t-Plot", obtidas a partir das isotermas de adsorção de nitrogênio das amostras estudadas.

Todas as isotermas apresentam perfis do tipo IV, que são característicos de sólidos mesoporosos, contendo poros com diâmetros na faixa de 20 a $500 \AA$. Por outro lado, verifica-se uma mudança no perfil da histerese das isotermas das amostras ARG-03 e ARG-04 em relação ao perfil das amostras natural e ARG-02, que é alterado do tipo $\mathrm{H} 4$ para o tipo H3 após os respectivos tratamentos. As histereses dos tipos $\mathrm{H} 3$ e $\mathrm{H} 4$ são características de materiais lamelares que possuem poros do tipo fenda ${ }^{16}$. A histerese do tipo H4 é obtida com materiais contendo microporos, isto é, poros com diâmetro inferior a $20 \AA$ A. Este resultado indica uma mudança na textura do material com os tratamentos efetuados tanto em meio básico modificado, quanto em meio ácido.

$\mathrm{Na}$ Tabela 5 estão apresentados os valores de área específica BET $\left(S_{\mathrm{BET}}\right)$, volume de poros, diâmetro médio de poro $\left(\mathrm{D}_{\mathrm{p}}\right)$, volume de microporos e área externa $\left(\mathrm{S}_{\mathrm{EXT}}\right)$, determinados a partir das isotermas de adsorção de nitrogênio das amostras natural e tratadas.

A análise textural da argila purificada (ARG-01) não apresenta variação em relação à amostra natural. $\mathrm{O}$ material natural apresenta $36 \%$ de microporosidade em relação ao volume total de poros. Quando a argila natural é comparada com a amostra ARG-02, verifica-se que não há variação textural importante após o tratamento com DCB clássico.
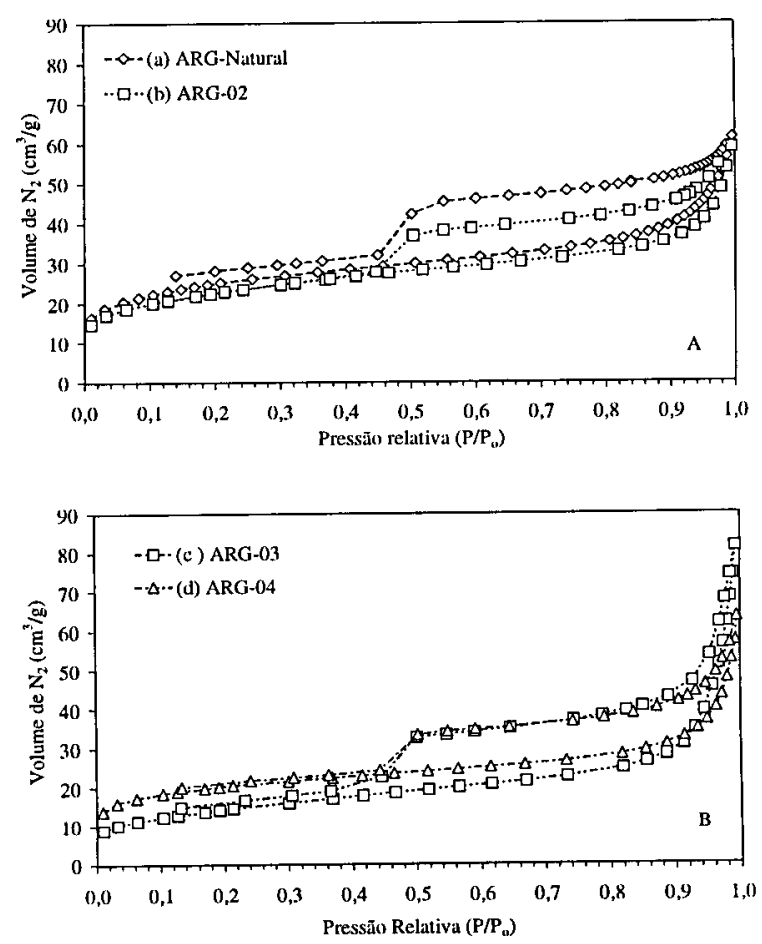

Figura 8. Isotermas de adsorção e dessorção de nitrogênio obtidas a partir das amostras estudadas: argila natural (a-ARG-Natural), argilas tratadas com DCB clássico (b-ARG-02), com DCB modificado (cARG-03) e com ácido cítrico (d-ARG-04), Isotermas do tipo IV, com histereses do tipo $\mathrm{H} 4$ (a) e $\mathrm{H3}(\mathrm{B})$.

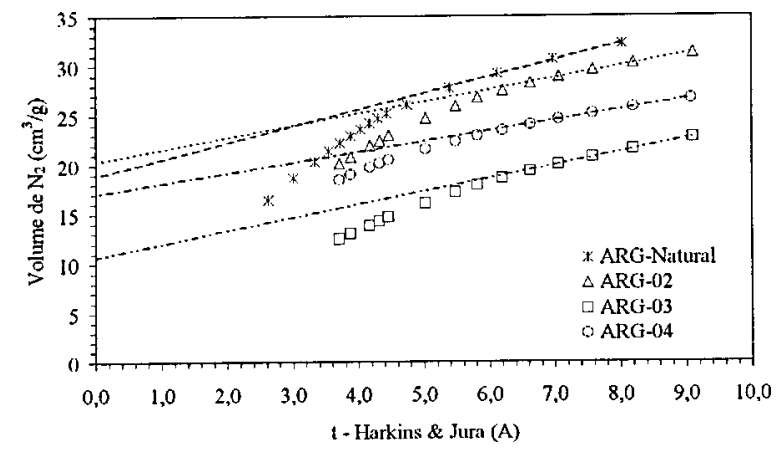

Figura 9. Avaliação do volume de nitrogênio adsorvido nos microporos das argilas estudadas como função da espessura de filme t estimada pela equação de Harkins \& Jura ${ }^{16}$.

Para a amostra tratada com DCB modificado (ARG-03) verifica-se uma diminuição do volume de microporos e queda da área específica $\left(S_{\mathrm{BET}}\right.$ de 80 para $\left.51 \mathrm{~m}^{2} / \mathrm{g}\right)$, o que indica modificação da textura com o aumento do tempo de tratamento com DCB. Estes resultados são similares aos obtidos por Stucki $\&$ Tessier ${ }^{14}$ e Lear \& Stucki ${ }^{15}$ que observaram, sob condições de altas concentrações de ditionito, a redução do ferro presente na rede cristalina da argila, alterando a relação $\mathrm{Fe}^{2+} / \mathrm{Fe}^{3+}$ e levando à queda da área específica, tendo como conseqüência o colapso da estrutura. Este efeito de diminuição da área específica $\left(S_{\text {BET }}\right.$ de 88 para $3 \mathrm{~m}^{2} / \mathrm{g}$, Tabela 5) em condições drásticas de tratamento (ARG-02R) foi observado quando foram utilizados dois ciclos de tratamento com $1,0 \mathrm{~g}$ de ditionito de sódio por ciclo $(2,0 \% \mathrm{~m} / \mathrm{v})$ ao invés de $0,80 \mathrm{~g}(1,6 \% \mathrm{~m} / \mathrm{v})$.

$\mathrm{O}$ tratamento feito na amostra ARG-02 com ácido cítrico (ARG-04) produz uma pequena queda do volume de microporos (cerca de 19\%), porém não afeta de forma significativa a área específica desta amostra $\left(S_{\text {BET }}\right.$ de 80 para $\left.71 \mathrm{~m}^{2} / \mathrm{g}\right)$. 
Tabela 5. Avaliação textural por adsorção de nitrogênio: área específica BET, volume de poros, diâmetro médio de poro, volume de microporos e área externa.

\begin{tabular}{lccccc}
\hline Amostra & $\begin{array}{c}\mathrm{S}_{\mathrm{BET}} \\
\left(\mathrm{m}^{2} / \mathrm{g}\right)\end{array}$ & $\begin{array}{c}\text { Volume de poros } \\
\left(\mathrm{cm}^{3} / \mathrm{g}\right)\end{array}$ & $\begin{array}{c}\mathrm{D}_{\mathrm{P}} \\
(\AA)\end{array}$ & $\begin{array}{c}\text { Volume de microporos } \\
\left(\mathrm{cm}^{3} / \mathrm{g}\right)\end{array}$ & $\begin{array}{c}\mathrm{S}_{\text {EXT }} \\
\left(\mathrm{m}^{2} / \mathrm{g}\right)\end{array}$ \\
\hline ARG-Natural & 88 & 0,087 & 40 & 0,031 & 24 \\
ARG-01 & 87 & 0,086 & 40 & 0,034 & 19 \\
ARG-02 & 80 & 0,091 & 46 & 0,032 & 19 \\
ARG-03 & 51 & 0,115 & 89 & 0,017 & 21 \\
ARG-04 & 71 & 0,081 & 35 & 0,026 & 17 \\
ARG-02R* & 3 & 0,031 & - & 0,002 & - \\
\hline
\end{tabular}

* A amostra ARG-02R foi preparada com 1,0 g de ditionito de sódio por ciclo de tratamento para $10 \mathrm{~g}$ de argila purificada (ARG01), com dois ciclos de tratamento.

Segundo Jovanovic \& Janackovic ${ }^{18}$, amostras de argilas tratadas com ácido mineral concentrado apresentam aumento da área específica, além dos demais parâmetros texturais (volume de poros, volume de microporos). É possível que o $\mathrm{pH}$ empregado no tratamento não tenha sido suficiente para provocar a lixiviação, conforme foi observado por Jovanovic \& Janackovic $^{18}$, que trabalharam com ácido concentrado (na faixa de 0,5 a $4,0 \mathrm{~mol} / \mathrm{L})$.

É importante ressaltar que o ácido cítrico é um ácido fraco e tem um agente complexante como contra-íon (o íon citrato), o qual complexa com metais como alumínio, ferro e magnésio, dentre outros, presentes na argila. Desta forma, a remoção dos metais deve ocorrer principalmente através do ataque do complexante citrato, e não por um mecanismo de lixiviação semelhante ao observado nos tratamentos com ácido mineral.

Os tratamentos em meio básico proporcionaram melhores indicativos de manutenção da estrutura da argila. Este fato propicia a utilização do material tratado com o método DCB na produção de catalisadores, tais como argilas pilarizadas, já que o uso destes catalisadores é determinado, dentre outras, pelas propriedades texturais (área específica, volume de poros, etc). Portanto, é importante avaliar a quantidade de ditionito de sódio e o tempo de tratamento utilizado para obter uma remoção máxima de ferro, sem alterar de forma significativa a textura e a estrutura da argila.

\section{CONCLUSÕES}

O tratamento em meio básico empregando o método de DCB é mais seletivo para extração de ferro, em relação à remoção de alumínio, do que o tratamento feito em meio ácido. Tanto o aumento do tempo de tratamento em meio básico, quanto o tratamento em meio ácido afetam a textura e a estrutura da argila. $\mathrm{O}$ aumento da concentração de ditionito de sódio no tratamento para a remoção de ferro com o método DCB provoca queda na área específica BET. O tratamento em meio básico realizado com trinta minutos e um total de $1,6 \mathrm{~g}$ de ditionito por $10 \mathrm{~g}$ de argila foi a condição experimental mais adequada para extração seletiva de ferro sem alterações significativas na argila.

\section{AGRADECIMENTOS}

O autores agradecem a MPL do grupo UBM, pelo fornecimento da bentonita natural, ao professor Luis Augusto $\mathrm{H}$. Torrones (Eng. de Materiais/UENF) pelo apoio nas análises de EDS/TEM, aos químicos Dr. Hosan A. A. A. Rehin, Lucia M.
Limoeiro Geraldo e Najla M. Estrada (Diquim/CENPES/ Petrobrás) pela colaboração nas análises de DRX e FRX, e ao CNPq pela bolsa de IC e pelo suporte financeiro.

\section{REFERÊNCIAS}

1. Rueda, E. H.; Ballesteros, M. C.; e Grassi, R. L.; Clays and Clay Minerals 1994, 40, 575-85.

2. Torres, R.; Blesa, M. A.; e Matijevic, E.; J. Colloid Interface Sci. 1990, 134, 475.

3. Mello, J. W. V. de; Barrón, V.; Torrent, J.; Soil Science 1998, 163, 122.

4. Trolard, F. et al.; Geochimica et Cosmochimica Acta 1995, $59,1285$.

5. Leite, S. Q. M; San Gil, R. A. da S.; Dieguez, L. C.; Revista Internacional de Información Tecnológica 1998, 9, 243.

6. Leite, S. Q. M; San Gil, R. A. da S.; Dieguez, L. C.; Actas do XVI Simposio Iberoamericano de Catálisis 1998, vol. III, 2045-2050.

7. Gomes, C. F.; Argilas - O que são e para que servem?, Fundação Caloustre Gulbenkien, Lisboa 1987

8. Souza Santos, P.; Ciência e Tecnologia de Argilas, vol.1, 2a. edição revisada e ampliada, editora Edgard Blücher. 1989

9. Adams, J. M.; Applied Clay Science 1987, 2, 309.

10. Wilson, M. J.; A Handbook of Determinative Methods in Clay Mineralogy, Blackie \& Son Limited 1987.

11. Mehra, O. P.; Jackson, M. L.; Clays and Clay Minerals 1960, 7, 317.

12. Claessen, M. E. C.; Barreto, W. O.; Paula, J. L.; Duarte, M. N.; Manual de métodos de Análise de Solo, $2^{a}$ edição; Embrapa - Ministério da Agricultura e do Abastecimento. 1997.

13. Stucki, J. W.; Bailey, G. W.; Gan, H.; Applied Clay Science 1996, 10, 417.

14. Stucki, J. W.; Tessier, D; Clays and Clay Minerals 1991, $39,137$.

15. Lear, P. R.; Stucki, J. W.; Clays and Clay Minerals 1989, $37,547$.

16. Gregg, S. J. \& Sing, K. S. W.; Adsorption, Surface area and Porosity, Acad. Press., London, 1982.

17. ASTM - Seach Manual - Hanawalt Method for Inorganic Compounds, Joint Committee on Powder Diffraction Data, 1601 Park Lane, Swarthmore, Pa. 19 081, EUA, 1973.

18. Jovanovic, N.; Janackovic, J.; Applied Clay Science 1991, $6,59$. 